\title{
NonEBV-related B-cell lymphoma in a renal transplant patient responding to acyclovir and reduction in immunosuppression
}

\author{
R.C.W. Wong and P. Harrison \\ Department of Renal Medicine, Southmead Hospital, Bristol BS10 5NB, UK
}

\begin{abstract}
Summary: A case of polyclonal B-cell pharyngeal lymphoma in a renal transplant patient is reported. No evidence of Epstein-Barr virus involvement was detected, but the lymphoma underwent complete remission with acyclovir and reduction in immunosuppression.
\end{abstract}

\section{Introduction}

Acyclovir has been used to treat Epstein-Barr virus (EBV)-related lymphomas, but we are unaware of any cases where it has been successful in a nonEBV-related lymphoma. We report such a case in a renal transplant patient.

\section{Case report}

A 60 year female had received her second cadaveric renal transplant in November 1989 for chronic renal failure of uncertain cause. Immunosuppression initially comprised prednisolone $15-30 \mathrm{mg}$ / day, azathioprine $25-100 \mathrm{mg} /$ day and cyclosporin A $250-450 \mathrm{mg} /$ day). Graft function was only moderate with serum creatinines between 162 and $340 \mu \mathrm{mol} / 1$.

She presented 5 months post-transplantation with recurrent left-sided earache. A pharyngeal mass was found obstructing the left Eustachian tube. Biopsy of this mass revealed a B-cell lymphoma with polyclonal proliferation of B-lymphocytes. Whole body computed tomographic (CT) scanning showed no lymphadenopathy either above or below the diaphragm. No evidence of EBV was found in the lymphoma by polymerase chain reaction or in situ hybridization techniques. There was no change in serum IgG antibody titres to EBV capsid antigen by indirect immunofluorescence during this episode.

Azathioprine was stopped, prednisolone and cyclosporin A were maintained at $15 \mathrm{mg}$ and $250 \mathrm{mg}$ daily respectively, and acyclovir was commenced, initially intravenously at $250 \mathrm{mg} /$ day,

Correspondence: P. Harrison, M.D., F.R.C.P.

Accepted: 30 May 1991 reduced after $24 \mathrm{~h}$ to $125 \mathrm{mg}$ /day for 4 days and subsequently orally at $800 \mathrm{mg} 5$ times/day. This was discontinued after 5 weeks and azathioprine restarted.

The B-cell lymphoma underwent remission and 3 months post-presentation no residual mass could be detected. She is currently well with a serum creatinine of $312 \mu \mathrm{mol} / \mathrm{l}(22 / 10 / 91)$ re-established on prednisolone $7.5 \mathrm{mg} /$ day, azathioprine $25 \mathrm{mg} /$ day and cyclosporin A $250 \mathrm{mg} /$ day. No further change in serum IgG antibody titres to EBV capsid antigen has occurred.

\section{Discussion}

It is recognized that there is an increased incidence of malignancy, including non-Hodgkin's lymphoma, in transplant patients. ${ }^{1}$ This has been largely attributed to the immunosuppressive agents used to prevent graft rejection. ${ }^{2}$ Cyclosporin A has been especially implicated as associated with lymphoproliferative disorders. ${ }^{3}$ Although it was initially suggested that maintaining cyclosporin dosage at non-toxic levels would reduce the risk of developing lymphomas, ${ }^{3}$ there has been a case report of non-Hodgkin's lymphoma in a patient whose plasma cyclosporin results were consistently in the non-toxic range $(<150 \mu \mathrm{g} / \mathrm{ml}) .{ }^{4}$ In our patient, cyclosporin levels had been elevated on 2 occasions prior to detection of the lymphoma.

Acyclovir has been used in Australia $^{5}$ and America' in the treatment of EBV associated B-cell lymphoproliferative disorders with mixed success. Hanto et al. ${ }^{1}$ found that the presence of polyclonal, as opposed to monoclonal, B-cell proliferations was a favourable predictor for response to acyclovir. They thus proposed that polyclonal tumours 
are dependent on EBV replication to repeatedly infect B-cells and produce polyclonal B-cells. Since acyclovir interferes with EBV replication, it will halt this process in polyclonal tumours. Monoclonal tumours are however due to B-cells which undergo autonomous replication independent of EBV and thus acyclovir will be ineffective.

In this case, however, there was no evidence of EBV infection either serologically or in the tumour mass itself. A Medline literature search did not find any reports of acyclovir inducing remission in nonEBV-related B-cell lymphomas. Tumour regression in this case is thus more likely to be related to the temporary reduction in immunosuppression by cessation of azathioprine. This concept has been supported by Starzl et al. ${ }^{2}$ as a useful method for inducing lymphoma regression without the need for more aggressive and dangerous therapy. This same group also reported that in their patients, graft function did not deteriorate

\section{References}

1. Hanto, D.W., Gajl-Peczalska, K.J., Frizzera, G. et al. Epstein-Barr virus (EBV) induced polyclonal and monoclonal B-cell lymphoproliferative diseases occurring after renal transplantation. Ann Surg 1983, 198: 356-369.

2. Starzl, T.E., Porter, K.A., Iwatsuki, S. et al. Reversibility of lymphomas and lymphoproliferative lesions developing under cyclosporin-steroid therapy. Lancet 1984 , i: 583-587.

3. Beveridge, T., Krupp, P. \& McKibbin, C. Lymphomas and lymphoproliferative lesions developing under cyclosporin therapy. Lancet 1984, i: 788. significantly with the temporary reduction/removal of immunosuppression, as was the case in our patient.

This case thus re-illustrates the fact that lympho- $\stackrel{.}{.}$ proliferative disorders in transplant patients need $\overrightarrow{\vec{\rho}}$ not necessarily indicate a poor outcome. Furthermore, as there is a possible advantage with early anti-viral treatment, before the EBV-dependent polyclonal tumours become autonomous monoclonal tumours, and acyclovir is a relatively safe drug, we suggest that it should be used sooner $c$ rather than later in the treatment of B-cell lym- $\overrightarrow{0}$ phomas in transplant patients whether or not they are associated with demonstrable EBV infection.

\section{Acknowledgement}

We wish to thank Professor P.C.L. Beverley, ICRF Human Tumour Immunology Group, for his advice and assistance.

4. Johnson Bia, M. \& Flyf, W. Lymphoma and cyclosporin. Lancet 1984, i: 1408.

5. Walker, R.J., Tiller, D.J., Horvath, J.S. \& Duggin, G.G. Malignant lymphoma in a renal transplant patient on cyclos sporin A therapy. Aust NZ J Med 1989, 19: 154-155. 